\title{
RFID Localization Using Special Antenna Technique
}

\begin{abstract}
In this paper, a RFID localization method using special antenna technique is presented. By using an active RFID system with external dipole antenna the angle and the distance from the antenna to the RFID tag can be found based on the principle of null steering. Compared with other techniques, this method has a number of advantages such as simple design, easy to implement, low cost and high reliability.
\end{abstract}

Keywords: RFID, localization, antenna, null steering.

\section{Introduction}

Radio Frequency Identification (RFID) is a wireless communication device which uses a small RF transponder and a RF detector for the automatic identification of objects. In a typical RFID system the transponder can be an unpowered (passive) sticker or a small powered (active) key fob, the electronic reader has either an external or integrated antenna and is connected to a computer system to $\log$ the data received.

Real time location estimation (RTLE) or real time localization is increasingly gaining relevance especially for short range communications because of the enormous prospects in terms of applications it offers. Although several localization techniques have been proposed, precision in the accuracy of real time location estimation is still a factor that is yet to be achieved due to the shortcomings of each of the techniques. RFID could provide a good solution. According to detection range the localization using RFID can be classified into two techniques: indoor localization and outdoor localization. So far the research and development of the RFID-based localization techniques focus on their indoor applications. These techniques include the angle-related measurements such as Angle of Arrival (AoA) (Cremer et al., 2015; Azzouzi et al., 2011; Kulakowski et al., 2010) and the distance-related measurements such as Received Signal Strength Indicator (RSSI) (Zhang et al., 2014; Sansanayuth et al., 2013; Ni et al., 2011), Time Difference of Arrival (TDoA) (Popa et al., 2010; Bailey at al., 2007), Phase of Arrival (PoA) (Scherhaufl et al., 2015; Scherhaufl et al., 2013) and Phase-Difference-ofArrival (PDoA) (Gortschacher et al., 2016; Scherhaufl et al., 2015). Although different approaches have been studied, these techniques still encounter some problems such as greater complexity of practical implementation, higher cost and lower accuracy, which have limited their practical applications. In order to improve RFID localization techniques a number of methods using new antenna design, such as phased antenna array (Huiting et al., 2015; Lee et al., 2015), leaky wave antenna (Liu et al., 2014), circularly polarized antennas (Cremer et al., 2014) and folded compact antenna (Guerchoucheet al., 2014), have been proposed. However, all these methods can only be used for indoor applications. In recent years, due to the pressing needs of our society, a great deal of attention has been directed toward developing effective tracking and localization techniques to be used in healthcare and disaster search and rescue operations. It is clear that these techniques should have good capability of working in outdoor environment. Several outdoor localization methods or systems 
using RFID in above areas have been reported (Ruan, 2016; Yang et al., 2016; Vojtech et al., 2015; Lucianaz et al., 2015; Vojtech, Neruda, Hrad et al., 2015). Although these methods have achieved very interesting results, most of them have a drawback: They need to combine active RFID technology with GPS receiver, which has limited their applications as GPS signal may not be available in some environments (James et al., 2012), they may also suffer from high power consumption, high cost and lower accuracy. In order to overcome above drawback, the authors in (Vojtech, Neruda, Hrad et al., 2015) have presented an outdoor localization technique using active RFID. However, the technique may not be practical for disaster management applications because (i) The system uses three RFID receiving stations, each station has 8-channel antenna array, making the implementation of the system very complicated; (ii) The system needs a number of reference positions, which requires sophisticated signal processing methods.

In this paper, an outdoor localization method using UHF active RFID technology and dipole antenna is presented. The proposed system includes active RFID reader, tag and external antenna. The angle from the antenna to the tag can be found by using the principle of the null steering. The null steering works by exploiting areas of the antenna's field where it cannot receive a signal, which is called the null field. The concept of this research was to design a system that is capable of tracking the position of RFID tag in free-space, the ways to achieve this would be using rotating dipole antenna or multiple dipole antenna array to give a directional bearing to the tag, furthermore when two arrays are combined at a set distance apart the system also allows the calculation of the range to target, allowing full vector mapping of multiple RFID tags in free space.

\section{Principle of operation}

\subsection{Null steering principle with rotating antenna}

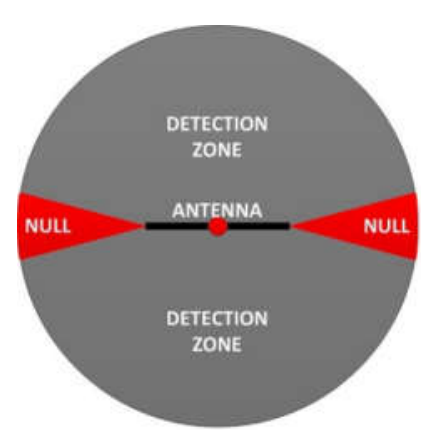

Figure 1 Null field concept

In this research, dipole antenna was used which has defined null fields of approximately $20^{\circ}$ at each end of the antenna. As shown in Figure 1, the antenna radiation pattern consists of regions of energy radiation and regions of null radiation. Dipole antennas are known to have a kidney shaped radiation pattern with two null radiation regions located at each of the edges of the antenna; therefore, the antenna can detect signals received on the radiation area and receive zero signals on the null area. This property could be utilized to detect the angle of a certain radiating object in reference to the reader. In theory, if an object was detected while the antenna is rotated, then the least power received from the 
antenna is the angle at which the object is located due to this angle being the angle of the null radiating region. By rotating (steering) the antenna until the signal is unattainable it is possible to deduce the angle from the dipole to the target. Also, it is possible to reduce the angle of the null field, therefore increasing accuracy, by overlapping two antennas by an angle less than the null field (approximately $20^{\circ}$ ) as shown in Figure 2.

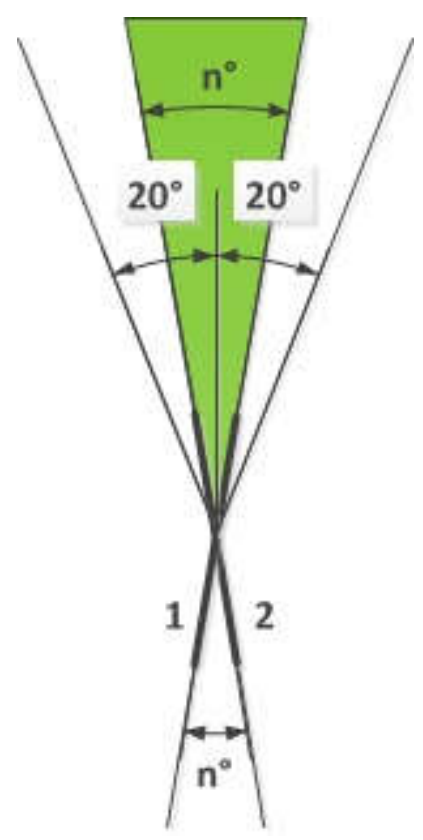

Figure 2 Overlapping null field concept

\subsection{Switched multiple antenna array}

The overlapping design shown in Figure 2, although useful for reducing the null field, requires the user to 'steer' the antenna, to calculate a bearing. A new design idea could be using multiple antennas in an array; each antenna's null field is lined up with the next, to form a null arc of approx $60^{\circ}$ (using 5 antennas). One at a time, each antenna is used to look for the tag, by recording on which antenna the tag is not visible it is possible to deduce the location of the tag to within $10^{\circ}$ without moving the array. This method is more robust than the steering principle as by confirming the tag is visible on the other antenna's it is possible to confirm the tag is within the test field, removing the problem of false positives, a problem that occurs frequently using the steering principle, where the signal is lost by moving out of range rather than out of sight. 


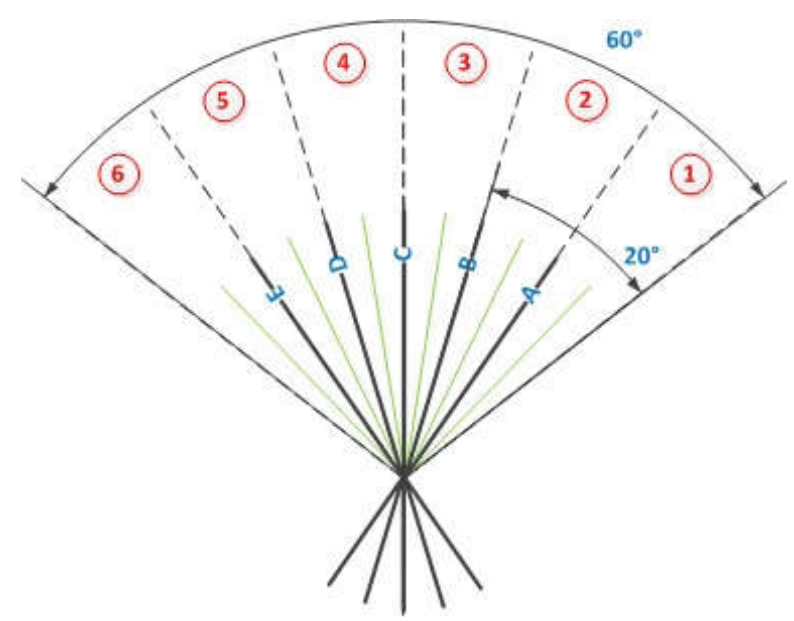

Figure 3 Switched array concept

Table 1 Location table for Figure 3

\begin{tabular}{|c|c|c|c|c|}
\hline Tag & \multicolumn{2}{|c|}{ Angle } & \multicolumn{2}{c|}{ Visible } \\
\hline & Min $^{\circ}$ & Max $^{\circ}$ & Yes & No \\
\hline 1 & 60 & 70 & B C D E & A \\
\hline 2 & 70 & 80 & C D E & A B \\
\hline 3 & 80 & 90 & A D E & B C \\
\hline 4 & 90 & 100 & A B E & C D \\
\hline 5 & 100 & 110 & A B C & D E \\
\hline 6 & 110 & 120 & A B C D & E \\
\hline
\end{tabular}

As an example, Figure 3 shows an antenna array in which Antenna A, B, C, D and E form an arc of $60^{\circ}$. The array can be used to find the tags (Tag $1,2,3,4,5$ and 6$)$ to within $10^{\circ}$. Table 1 shows the locating results. For example, as Tag 1 can be detected by Antenna B, C, D and E, but not by A, it can be deduced that Tag 1 is located in the null area of Antenna A, that is the area between $60^{\circ}$ and $70^{\circ}$. As can be seen, increased search arc could be achieved by adding more antennas at each end of the array; increased resolution can be achieved by adding secondary antennas between the primary, doubling the resolution to $5^{\circ}$.

\subsection{Localization technique}

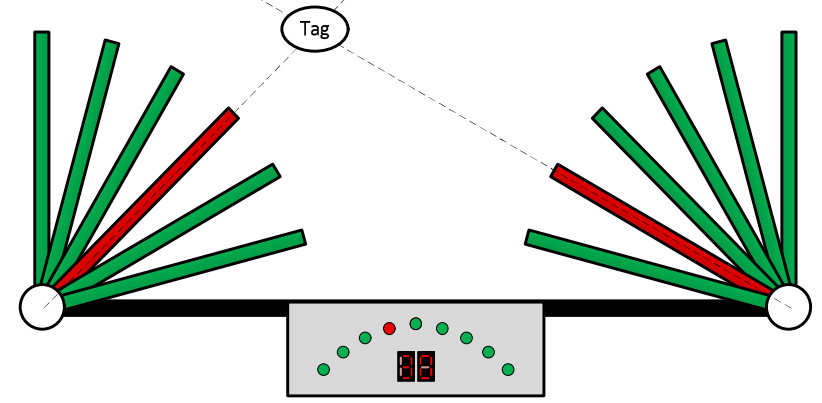

Figure 4 Dual antenna array localization system 


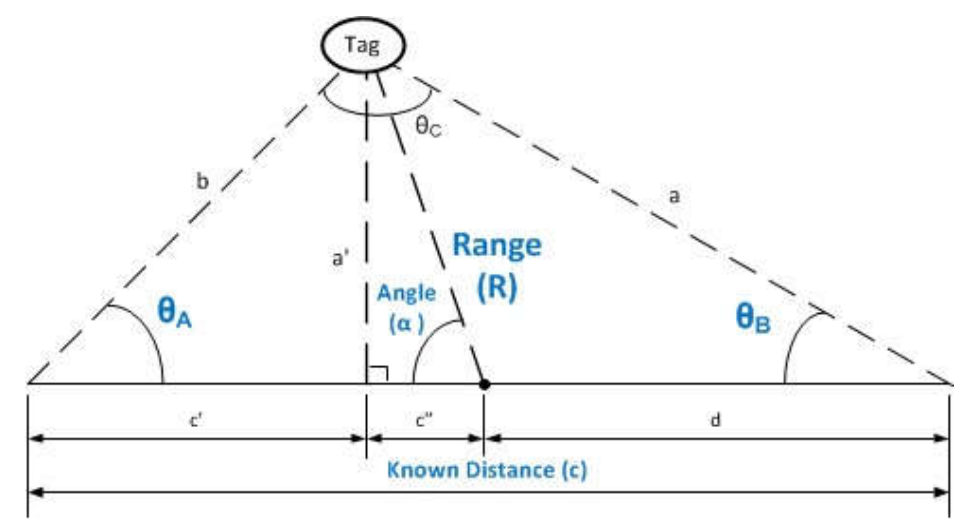

Figure 5 Determining the location using triangulation principle

Figure 4 shows how to realize the proposed localization system. The system consists of two rotating antennas or antenna arrays with a fixed distance apart. The operation principle is that each antenna or array will perform a sweep, locating the tag using the null steering principle and AoA method. Using AoA to determine the location of a specific object (tag) requires two angles towards the same object separated by a known distance in order to formulate a triangle with three known variables. Hence, it is possible to calculate the distance and location of the object with reference to the two points at which the angle was measured. Figure 5 illustrates the proposed localization technique. One antenna with a measured angle of $\theta_{A}$ and another with a measured angle of $\theta_{B}$ towards the tag, while the known distance between two antennas is $c$ (In Figure 5, $d=c / 2$ ), it is therefore possible to deduce the distances $a$ and $b$ using the following equation after calculating the third angle of the triangle

$$
\frac{a}{\sin A}=\frac{b}{\sin B}=\frac{c}{\sin C}
$$

It is then simple to divide the triangle into two right-angled triangles, as shown in Figure 5, and therefore, able to use Pythagorean Theorem to deduce the range $R$ and the angle $\alpha$ for the tag using the following equations

$$
\begin{gathered}
R=\sqrt{\left(\frac{2 d \sin \theta_{A} \sin \theta_{B}}{\sin \left(\theta_{A}+\theta_{B}\right)}\right)^{2}+\left(d-\left(\frac{2 d \cos \theta_{A} \sin \theta_{B}}{\sin \left(\theta_{A}+\theta_{B}\right)}\right)\right)^{2}} \\
\alpha=\tan ^{-1}\left(\frac{2 \sin \theta_{A} \sin \theta_{B}}{\sin \left(\theta_{A}+\theta_{B}\right)-2 \cos \theta_{A} \sin \theta_{B}}\right)
\end{gathered}
$$

By using a specific software, this information can be outputted directly to the user as range and direction or by a visual display. 


\section{Practical implementation and testing}

The above localization method has been demonstrated by using UHF RFID technology operated at 2 frequencies: $868 \mathrm{MHz}$ and $434 \mathrm{MHz}$.

\subsection{Using Eureka UHF RFID active kit}

\subsubsection{System components}

A Eureka UHF active kit (Avonwood Eureka, 2009) was used to demonstrate the RFID location technique. As shown in Figure 6, the kit is comprised of the following components: an RFID reader, six transponder tags and two wakeup antenna units.

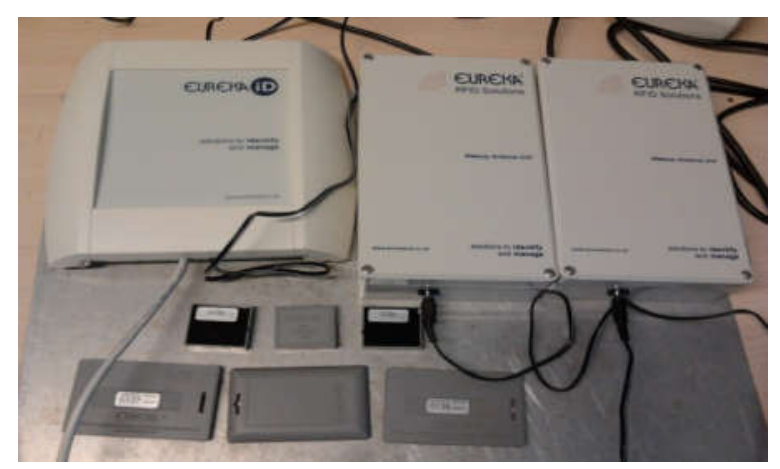

Figure 6 Eureka RFID system (Avonwood Eureka, 2009)

\section{RFID reader}

The Eureka RFID reader operates at a frequency of $868 \mathrm{MHz}$ and is capable of reading location tag data up to 100 meters. Table 2 shows the specifications for the RFID reader.

Table 2 Specification for Eureka RFID reader

\begin{tabular}{|c|c|}
\hline Specifications & Details \\
\hline RX Frequency & $868 \mathrm{MHz}$ \\
\hline Range & Up to $100 \mathrm{~m}$ \\
\hline LAN & $10 / 100$ Base-T Ethernet via RJ45 \\
\hline Operating Temperature & $-10^{\circ} \mathrm{C}$ to $+50^{\circ} \mathrm{C}$ \\
\hline Size & $200 \mathrm{~mm} \times 210 \mathrm{~mm} \times 48 \mathrm{~mm}$ \\
\hline weight & $0.7 \mathrm{~kg}$ \\
\hline Supply Voltage & $12 \mathrm{~V} \mathrm{DC}$ \\
\hline
\end{tabular}




\section{RFID tags}

The Eureka active RFID tags were used throughout the tests. The tags were designed to be worn as a lanyard around a person's neck. With the tags within about 5 meters from any wakeup unit, an electromagnetic field generated by the latter unit activates the tag(s), hence, causing it to send a prestored signal to the reader. Since the tag and reader operate at the same frequency, the reader receives all tag signals sent in a non-stop manner, demodulates and decodes them as digital data. The decoded signals are then sent to the PC via the TCP/IP communication link for display on the Eureka software. The two sets of pre-stored information are the tag ID and the wakeup ID of the unit that activated that particular tag.

\section{External antenna}

In order to improve the locating ability of the hardware system being used, the Eureka reader has been modified by using external dipole antenna to replace the onboard PCB antenna. With the external antenna, the regions of energy radiation were determined by steering the single antenna through $360^{\circ}$ or using an antenna array based on the null steering principle. Figure 7 shows the measured radiation pattern for the designed half-wave dipole antenna between $800 \mathrm{MHz}$ and $900 \mathrm{MHz}$.

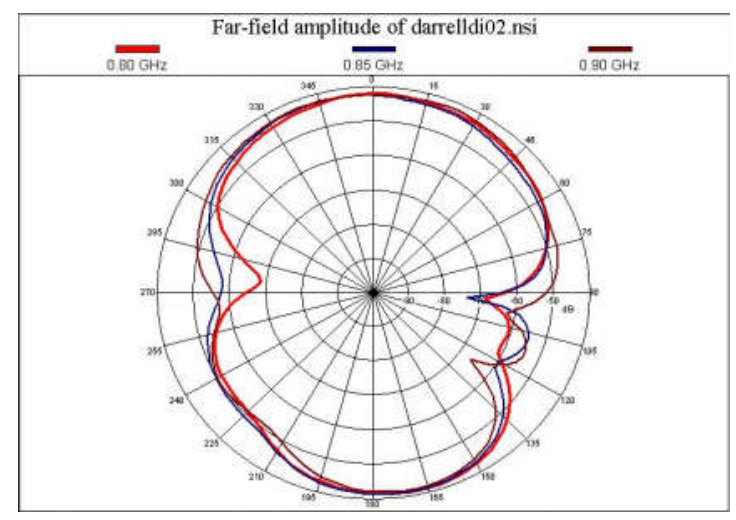

Figure 7 Radiation pattern of half-wave dipole antenna

4 A computer with the Eureka software installed.

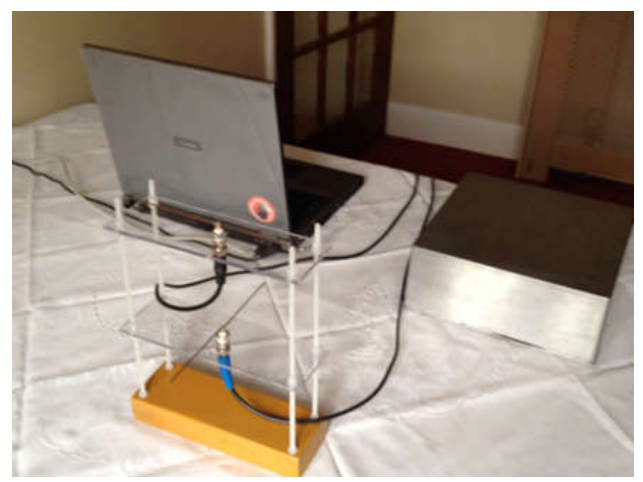

Figure 8 System set-up 


\subsubsection{System set-up}

Figure 8 shows the system set-up, where the RFID reader is in an electromagnetic shielding box. The first test was to connect the system to the computer. Figure 9 shows the software recognizing the connectivity between the computer and the RFID reader.

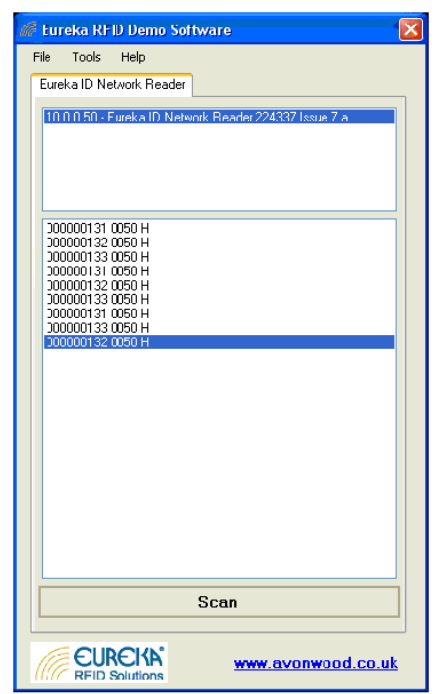

Figure 9 Connectivity between RFID reader and computer

After it was confirmed that the system was working as it expected, several tags were placed at various distances away from the reader to confirm that the reader was able to send the relevant data to the computer relating to the unique identification number assigned to each tag.

\subsubsection{Measurement results}

The minimum and maximum areas at which the null radiation angle is present were measured when the RFID location tags were placed at distances of 25 meters and 35 meters away from the RFID reader. Figure 10 shows the measurement results for the distance of 25 meters. As can be seen, the minimum null angle is $120.4^{\circ}$, and the maximum null angle is $140.1^{\circ}$, which indicates that the tag to be detected is located between these two angles (the null radiation angle is $19.7^{\circ}$ ). The measurement results shown in Figure 11 reveal that the tag to be detected is located between $93.4^{\circ}$ and $112.1^{\circ}$ for the distance of 35 meters. 


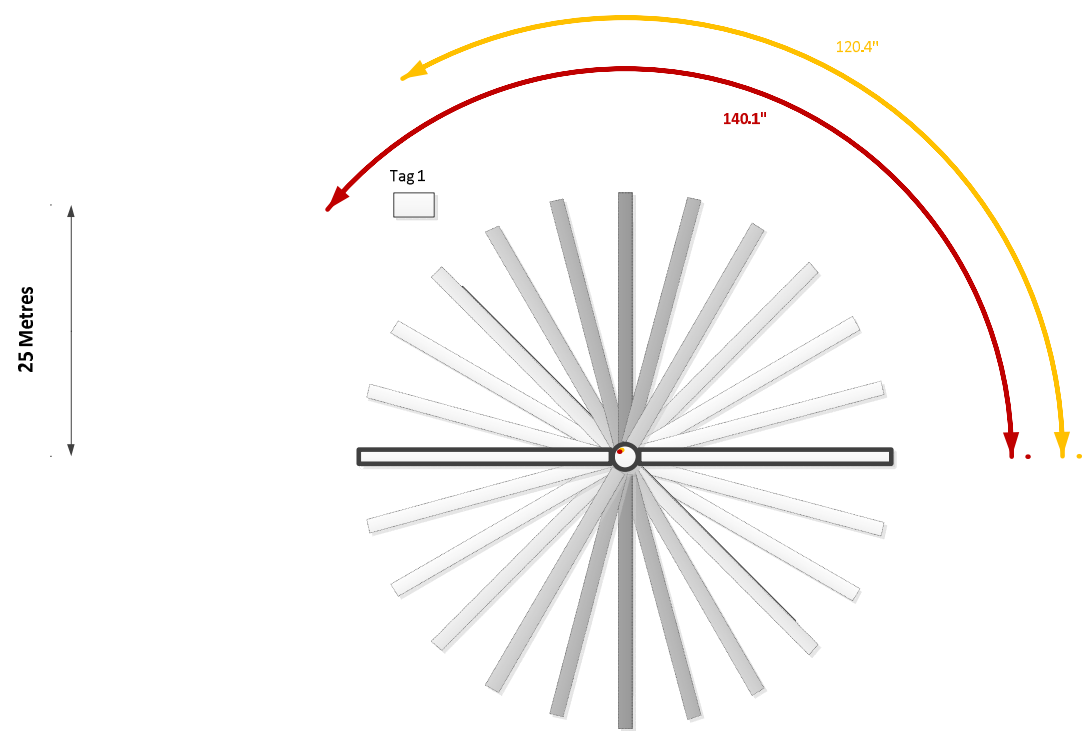

Figure 10 Null radiation angle for a tag $(25 \mathrm{~m})$

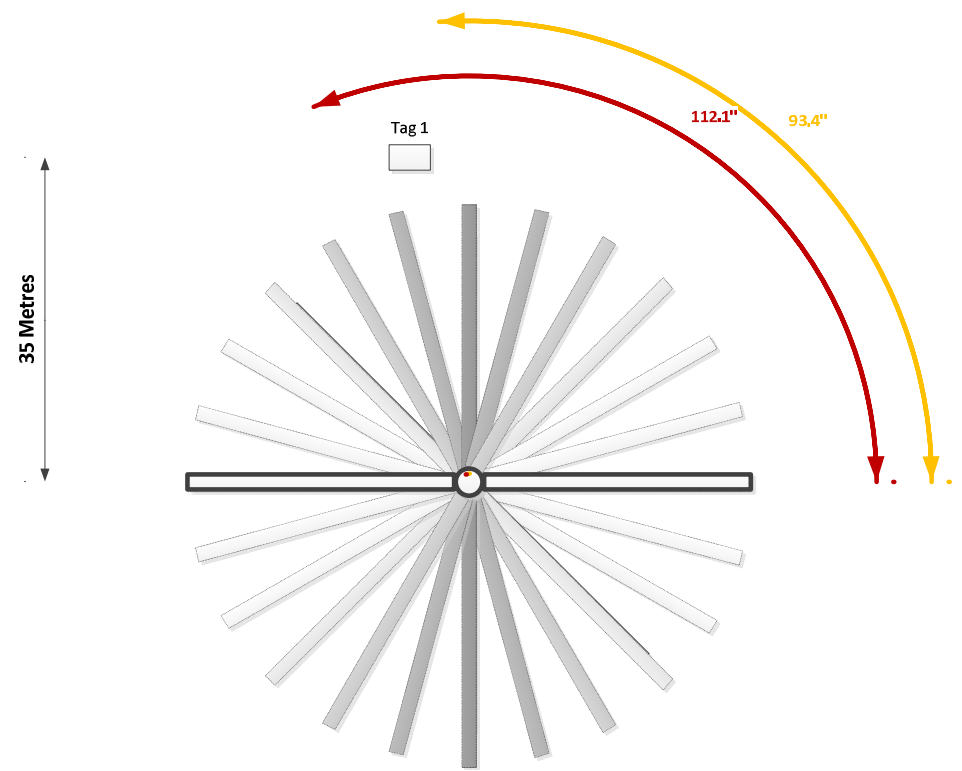

Figure 11 Null radiation angle for a tag $(35 \mathrm{~m})$

As shown in Figure 12, the localization using the null steering principle can be performed by the following way: Firstly, place a RFID reader with a rotating dipole antenna or an antenna array to the point $A$ and find the null radiation angle $\alpha$; then, move the reader to the position $B$ with a known distance $l$ and find the corresponding null radiation angle $\beta$; finally, determine the positions of the point $a, b, c$ and $d$ by using the method shown in Figure 5. Thus, the tag to be located is in the region surrounded by these points. 


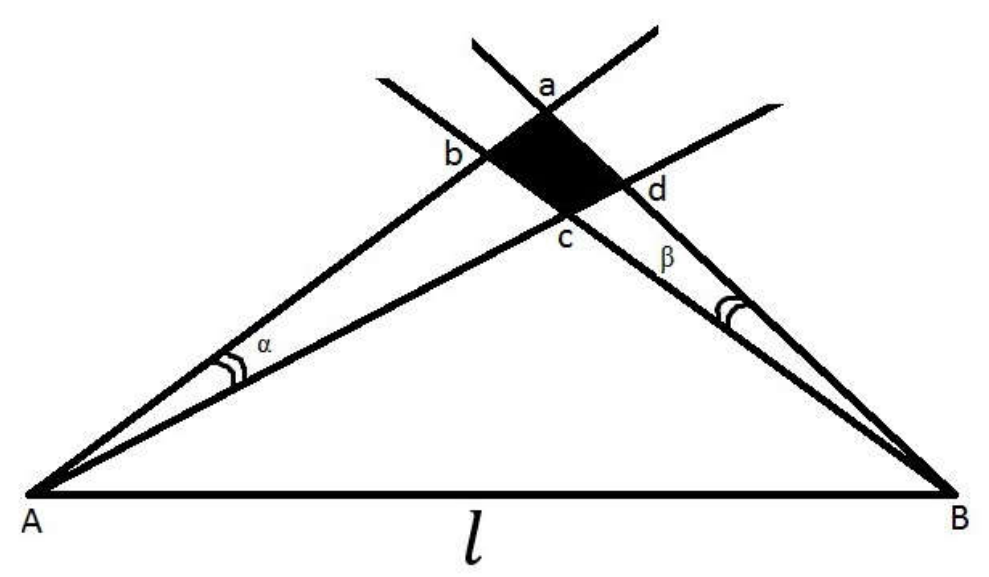

Figure 12 Localization using the null steering principle

\subsection{MHz active RFID localizer}

The localization using the null steering principle has also been demonstrated by $434 \mathrm{MHz}$ active RFID technology with received signal strength indicator (RSSI).

\subsubsection{System design and implementation}

\section{RFID tag}

An active RFID tag was designed using a QAM-TX1 radio transmitter with a MBED microcontroller. The tag has many requirements that need a number of components communicating together; these components include the microcontroller, the transmitter module, the battery and the antenna.

The communication protocol was chosen to be serial communication as it provides the ease of communication between electronic circuits and computer architectures. The basic communication settings were chosen to be as follows:

- Baud rate : 1200

- Parity : Even

- Stop bits : 2

The MBED microcontroller is programmed to send bursts of data every second when activated and provides ease of programming and communication to the PC using the USB port, allowing the programming of the microcontroller without the requirement of any additional circuitry.

The transmitter module used was chosen to be the "RF Link Transmitter 434MHz" as it operates at the $434 \mathrm{MHz}$ band allowing flexible design for the antennas and high rate for the data transmission.

A dipole antenna was designed to operate at the $434 \mathrm{MHz}$ frequency and to serve as the transmitter antenna. Figure 13 shows the full RFID tag system. 


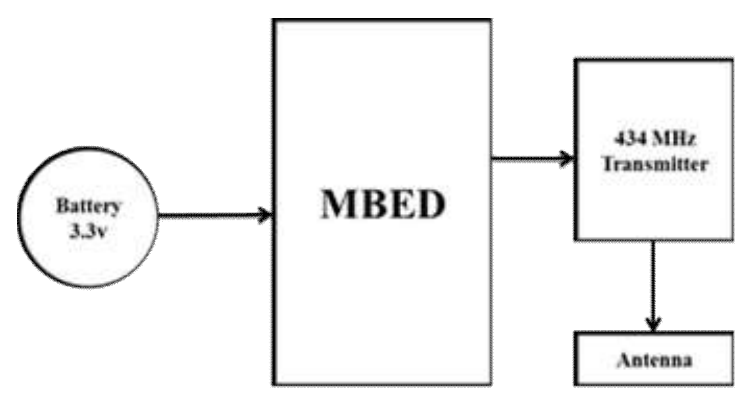

Figure 13 RFID tag block diagram

\section{RFID localizer}

Figures 14 shows the block diagram of the RFID localizer. As can be seen, the RFID localizer has 3 parts: MBED microcontroller, readers and PC. Each of the 2 readers consists of an RRQ3-433 receiver, a dipole antenna and a stepper motor. The microcontroller is connected to a PC that performs all the location calculation as well as plotting the tag details on the screen. The readers are separated by a customizable distance providing the flexibility of different applications.

RRQ3-433 was chosen as the receiver module in the reader due to its compatibility with the transmitter module and the ability to measure the RSSI of the signal. This module is connectable directly with the receiver antenna. The receiver sends the received data to the MBED microcontroller, which is functioning as a 'collaborator'. The MBED is responsible for communicating with both readers to $\log$ the data received from each one and rotating the motors in the correct time and order. In addition, the MBED microcontroller stores the logged data into two "CSV" files that can be read and edited by most word processing applications such as Windows notepad, and spread sheet applications such as Microsoft Excel. Once the two files are saved on the MBED memory, the PC can then read these files and apply the localization algorithm to determine the location of the tags.

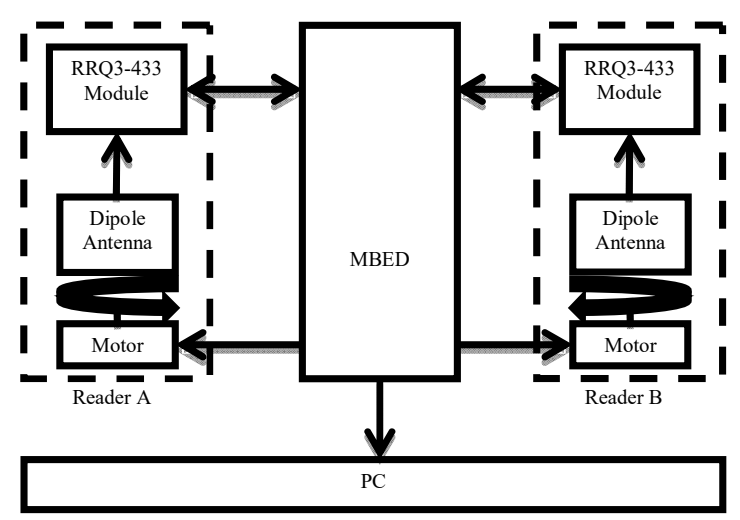

Figure 14 RFID localizer block diagram. 


\subsubsection{Measurement results}

A number of tests were carried out to demonstrate the performance of the system. In the tests, the minimum and maximum angles where null radiation occurred were recorded at distance ranges from 30 to 40 meters. The readers detect the signal strength by measuring the RSSI of the received signal and send the measured results to the PC for logging. After a full rotation cycle is measured and recorded at the PC, the respective tag angle is calculated according to the least RSSI received and detected by the null in the radiation pattern. Table 3 presents the measurement results with a distance of 10 meters between two readers. By referring to Figure 5, it can be seen that the two angles $\theta_{A}$ and $\theta_{B}$ are $70^{\circ}$ and $30^{\circ}$, respectively. It has shown that the system provided a significant level of accuracy. The system was designed to allow other information such as temperature etc. to be added to the data from the tag. A tolerance of $+/-1 \mathrm{~m}$ is applicable to the location accuracy of the system.

Table 3 Measurement results for the angles based on the null steering and RSSI

\begin{tabular}{|c|c|c|}
\hline Angle & $\begin{array}{c}\text { Reader A } \\
\text { (RSSI) }\end{array}$ & $\begin{array}{c}\text { Reader B } \\
\text { (RSSI) }\end{array}$ \\
\hline 90 & 5 & 5 \\
\hline 80 & 2.5 & 5 \\
\hline 70 & 1.3 & 5 \\
\hline 60 & 2.5 & 5 \\
\hline 50 & 5 & 4 \\
\hline 40 & 5 & 1.2 \\
\hline 30 & 5 & 0.7 \\
\hline 20 & 5 & 1.2 \\
\hline 10 & 5 & 4 \\
\hline 0 & 5 & 5 \\
\hline
\end{tabular}

\section{Conclusion}

In this paper, a new outdoor RFID localization technique has been demonstrated. Using active RFID technology and the principle of null steering with dipole antennas, the proposed system is able to determine the location of RFID tag in unknown space with good accuracy. Table 4 shows the comparison between the proposed system and other outdoor RFID localization techniques. As can be seen, the system doesn't need GPS signal and reference tags. Also, in most of outdoor applications the system can use only one reader with a rotating dipole antenna to perform localization by moving the reader from one position to another position in a search area specified by the reader. Because the system uses the least number of reader as well as simple and cheap dipole antenna, the complexity of implementation and cost can be reduced.

The design proposed in this research is a simple and effective way of locating objects using RFID. When used in disaster search and rescue operations, the system described by this research could allow the search team to reduce the area needed to be physically searched greatly. 
Table 4 Comparison of outdoor localization methods

\begin{tabular}{|c|c|c|c|c|}
\hline Reference & $\begin{array}{c}\text { Number of } \\
\text { readers }\end{array}$ & $\begin{array}{c}\text { GPS is } \\
\text { needed? }\end{array}$ & $\begin{array}{c}\text { Reference tag } \\
\text { is needed? }\end{array}$ & $\begin{array}{c}\text { Antenna } \\
\text { technique }\end{array}$ \\
\hline $\begin{array}{c}\text { Vojtech, Neruda, } \\
\text { Skapa et al. }\end{array}$ & 3 & yes & yes & $8-20$ clover leaf antennas \\
\hline $\begin{array}{c}\text { Vojtech, Neruda, } \\
\text { Hrad et al. }\end{array}$ & 3 & no & yes & 8 clover leaf antennas \\
\hline Lucianaz et al. & 1 & yes & no & 1 helical antenna \\
\hline Yang et al. & 2 & yes & no & $\begin{array}{c}2 \text { stub antennas and } 2 \\
\text { helical antennas }\end{array}$ \\
\hline $\begin{array}{c}\text { System proposed } \\
\text { in this paper }\end{array}$ & $1^{*}$ & no & no & 1 dipole antenna \\
\hline
\end{tabular}

* moving the reader from one position to another position

\# rotating antenna for required angles $\left(0^{\circ}-360^{\circ}\right)$

\section{References}

Azzouzi, S., Cremer, M., Dettmar, U., Knie, T., Kronberger, R. (2011) 'Improved AoA based localization of UHF RFID tags using spatial diversity', in Proc. 2011 IEEE International Conference on RFID-Technology and Applications, Sitges, Spain, pp. 174-180.

Bailey, K., Wiebe, B., Uribe, A. (2007) 'SensorFusion: Localization and tracking of sensors using RFID', in Proc. 2007 Earthquake Engineering Symposium for Young Researchers, Seattle, Washington, pp. 1-21.

Cremer, M., Pervez, A., Dettmar, U., Hudasch, C. (2015) 'Multichannel digital transmit beamforming experiments for RFID tag localization', in Proc. 2015 International EURASIP Workshop on RFID Technology (EURFID), Rosenheim, Germany, pp. 126-131.

Cremer, M., Pervez, A., Dettmar, U., Knie, T., Kronberger, R. (2014) 'Improved UHF RFID localization accuracy using circularly polarized antennas', in Proc. 2014 IEEE RFID Technology and Applications Conference (RFID-TA), Tampere, Finland, pp. 175-180..

Eureka RFID. http://www.avonwood.co.uk/.

Gortschacher, L., Grosinger, J., Khan, H.N., Amschl, D., Priller, P., Muehlmann, U., Bosch, W. (2016) 'SDR based RFID reader for passive tag localization using phase difference of arrival techniques', in Proc. 2016 IEEE/MTT-S International Microwave Symposium (IMS), San Francisco, USA, pp. $1-4$.

Guerchouche, K., Rolland, N. (2014) 'A folded compact antenna for broadband RFID UHF applications', in Proc. IEEE International Conference on Antenna Measurements \& Applications, Antibes, France, pp. 1-4.

Huiting, J., Kokkeler, A.B.J., Smit, G.J.M. (2015) 'Near field phased array DOA and range estimation of UHF RFID tags', in Proc. 2015 International EURASIP Workshop on RFID Technology (EURFID), Rosenheim, Germany, pp. 103-107. 
James, S., Verrinder, R.A., Sabatta, D., Shandi, A. (2012) 'Localization and mapping in GPS-denied environments using RFID tags', in Proc. 2012 5th Robotics and Mechatronics Conference of South Africa, Johannesburg, South Africa, pp.1-4.

Kułakowski, P., Vales-Alonso, J., Egea-Lopez, E., Ludwin, W., Garcia-Haro, J. (2010) 'Angle-ofarrival localization based on antenna arrays for wireless sensor networks', Computers and Electrical Engineering, Vo. 136, No. 6, pp. 1181-1186.

Lee, W.S., Tae, H.S., Yu, J.W. (2015) 'Quadruple-feed beam-controlled antenna array for the localization of ultra-high-frequency radio-frequency identification tags', IET Microwave, Antenna \& Propagation, Vo. 9, No. 9, pp. 923-932.

Liu, Q., Fusco, V., Zelenchuk, D. (2014) 'Frequency scanning antenna for target location applications', in Proc. 8th European Conference on Antenna and Propagation (EuCAP 2014), Hague, The Netherlands, pp. 2059-2061.

Lucianaz, C., Greco, G., Bertoldo, S., Allegretti, M. (2015) 'Real time outdoor localization of buries RFID tags through statistical methods', in Proc. 2015 International Conference on Electromagnetics in Advanced Applications (ICEAA), Torino, Italy, pp. 1152-1154.

Ni, L., Zhang, D., Souryal, M. (2011) 'RFID-based localization and tracking technologies', IEEE Wireless Communications, Vo. 18, No. 2, pp. 45-51.

Popa, V., Coca, E., Dimian, M. (2010) 'Applications of RFID systems - Localization and speed measurement'. INTECH Open Access Publisher, Rijeka, Croatia.

Ruan, W. (2016) 'Unobtrusive human localization and activity recognition for supporting independent living of the elderly', in Proc. 14th Annual IEEE International Conference on Pervasive Computing and Communications (PerCom 2016), PhD Forum, Sydney, Australia, pp. 1-3.

Sansanayuth, T., Suksompong, P., Taparugssanagorn, A. (2013) 'RFID 2D-localization improvement using modified LANDMARK with linear MMSE estimation', in Proc. 2013 13th International Symposium on Communications and Information Technologies (ISCIT), Surat Thani, Thailand, pp. 133-137.

Scherhaufl, M., Pichler, M., Schimback, E., Muller, D.J., Ziroff, A., Stelzer, A. (2013) 'Indoor localization of passive UHF RFID tags based on phase-of-arrival evaluation', IEEE Transactions on Microwave Theory and Techniques, Vo. 61, No. 12, pp. 4724-4729.

Scherhaufl, M., Pichler, M., Stelzer, A. (2015) 'Robust localization of passive UHF RFID tag arrays based on phase-difference-of-arrival evaluation', in Proc. 2015 IEEE Topical Conference on Wireless Sensors and Sensor Networks (WiSNet), San Diego, USA, pp. 47-49.

Scherhaufl, M., Pichler, M., Stelzer, A. (2015) 'UHF RFID localization based on phase evaluation of passive tag arrays', IEEE Transactions on Instrumentation and Measurement, Vo. 64, No. 4, pp. 913-922.

Vojtech, L., Neruda, M., Hrad, J., Bortel, R. (2015) 'Outdoor localization technique using active RFID technology aimed for security and disaster management applications', in Proc. 2015 16th International Carpathian Control Conference (ICCC 2015), Szilvasvarad, Hungary, pp. 586-589.

Vojtech, L., Neruda, M., Skapa, J., Novotny, J., Bortel, R. (2015) 'Design of RFID outdoor localization system-RFID locator for disaster management', in Proc. 2015 5th International Conference on the Internet of Things (IoT), Seoul, South Korea, pp. 4-11. 
Yang, Z., Ganz, A. (2016) 'Infrastructure-less and calibration-free RFID-based localization algorithm for victim tracking in mass casualty incidents', in Proc. 2016 IEEE Symposium on Technologies for Homeland Security (HST), Waltham, USA, pp. 1-4.

Zhang, X., Akre, J-M., Baey, S., Fladenmuller, A., Kervella, B., Zancanaro, M.A., Fonseca, M. (2014) 'Towards localization of RFID tags based on experimental analysis of RSSI', in Proc. 2014 IFIP Wireless Days (WD), Rio de Janeiro, Brazil, pp. 1-4.

\section{Figures and Tables}

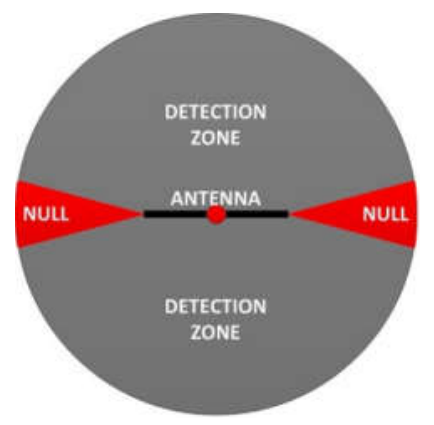

Figure 1 Null field concept

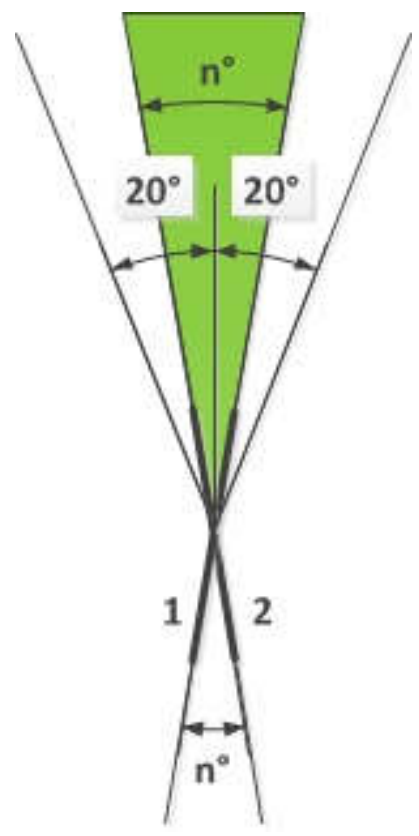

Figure 2 Overlapping null field concept 


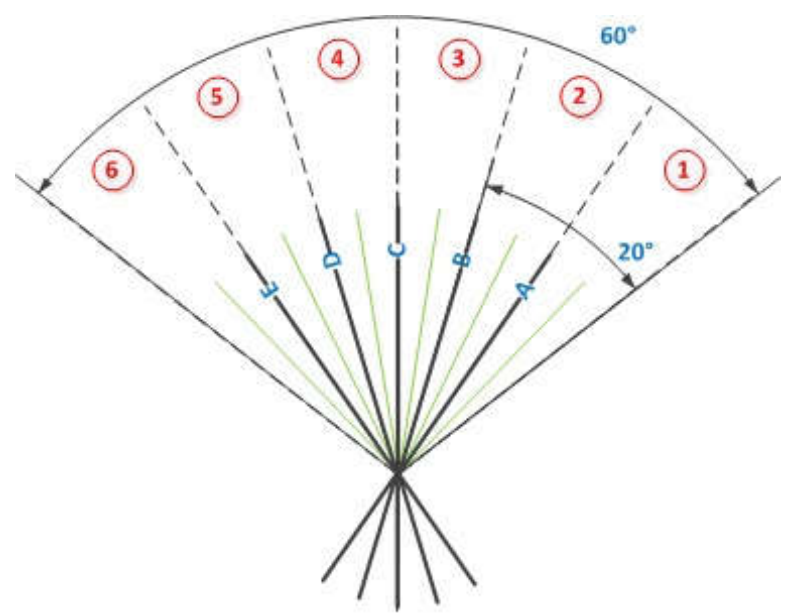

Figure 3 Switched array concept

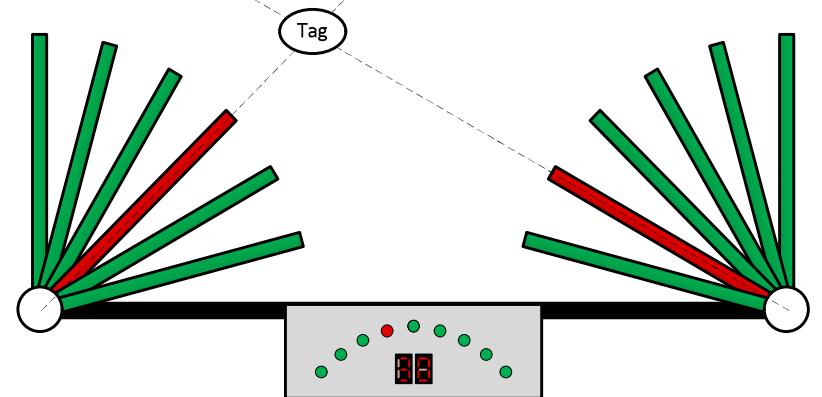

Figure 4 Dual antenna array localization system

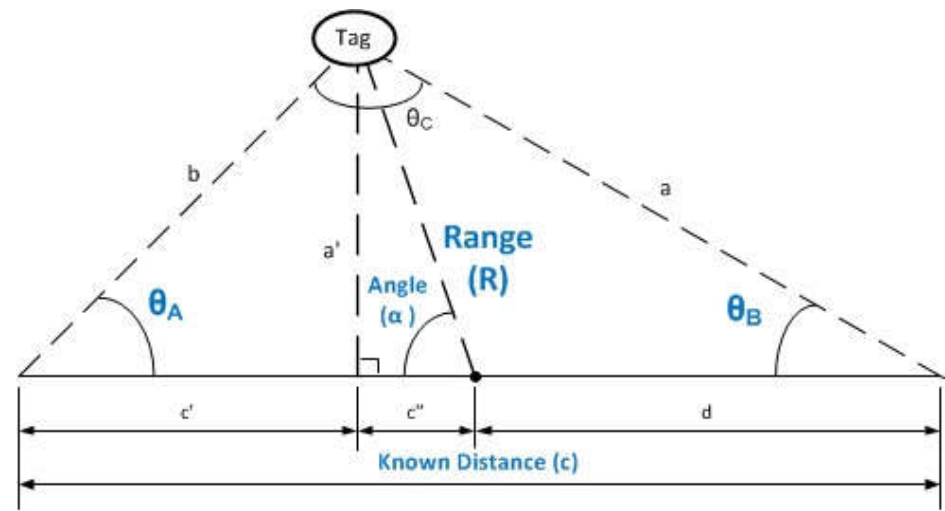

Figure 5 Determining the location using triangulation principle 


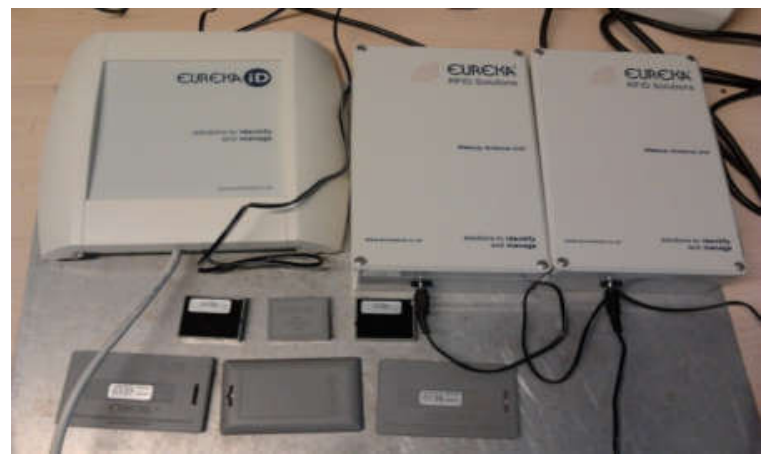

Figure 6 Eureka RFID system (Avonwood Eureka, 2009)

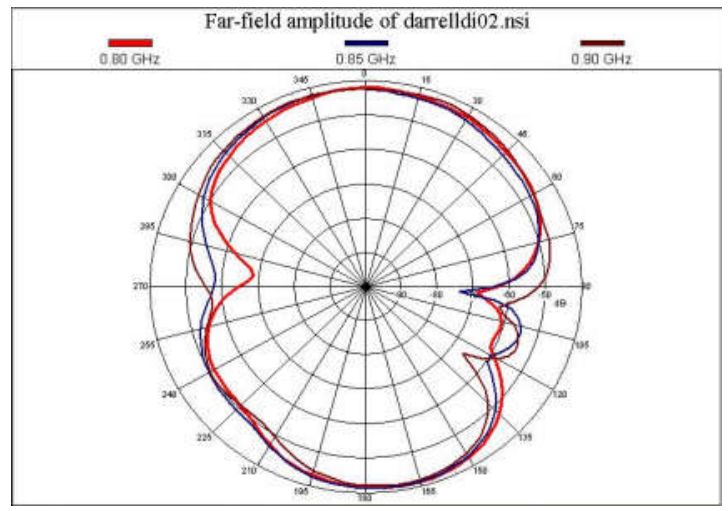

Figure 7 Radiation pattern of half-wave dipole antenna

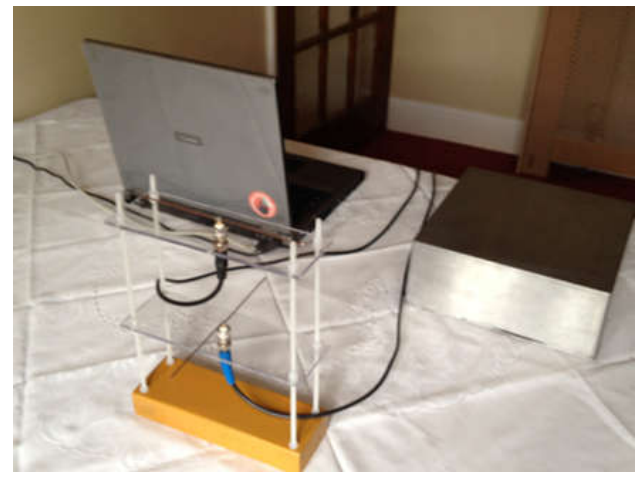

Figure 8 System set-up 


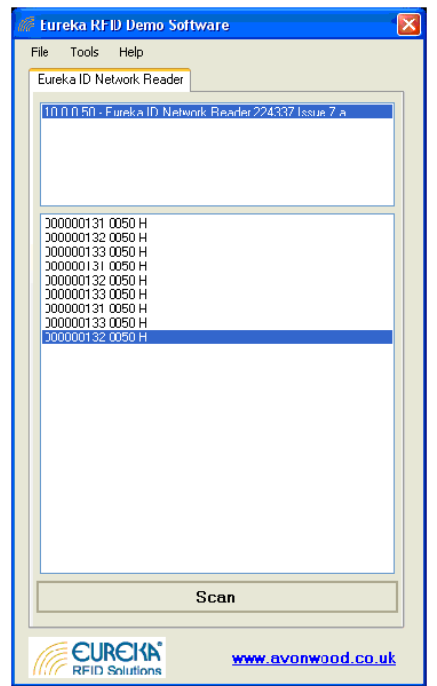

Figure 9 Connectivity between RFID reader and computer

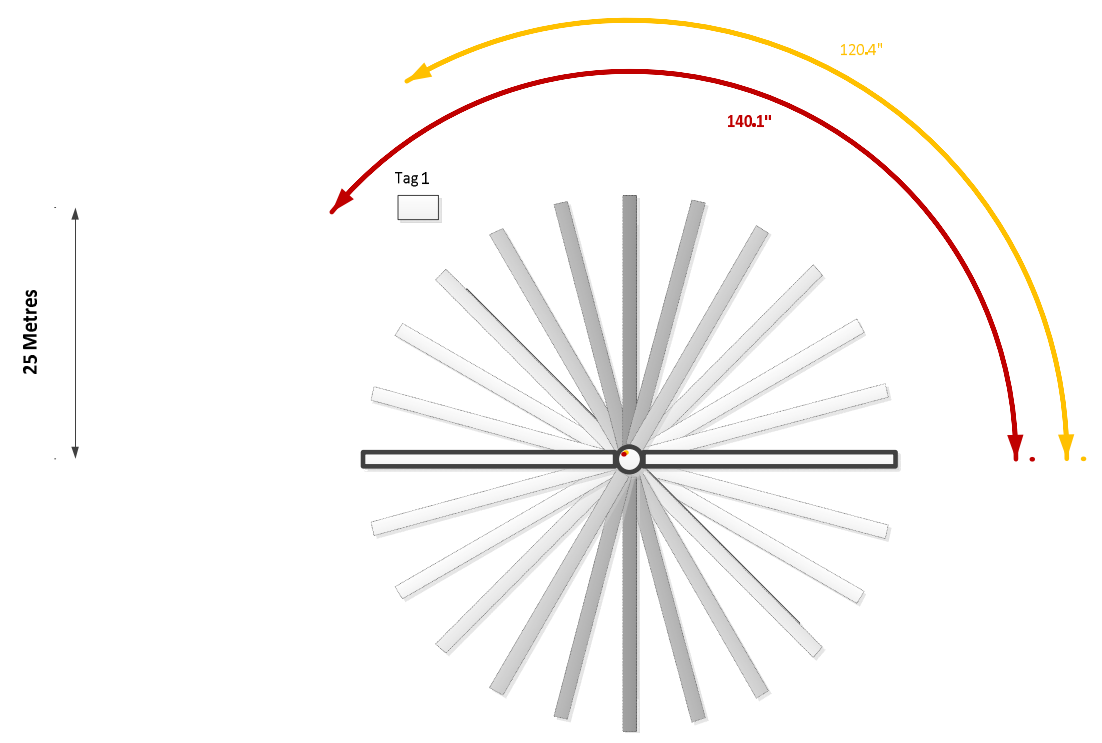

Figure 10 Null radiation angle for a tag (25m) 


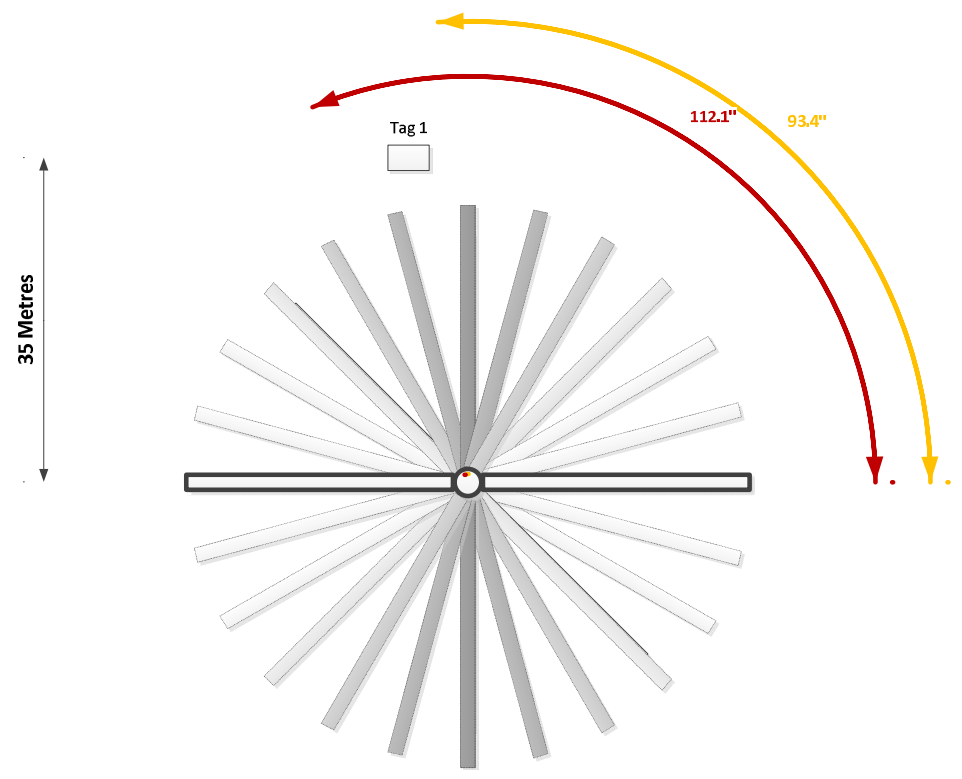

Figure 11 Null radiation angle for a tag $(35 \mathrm{~m})$

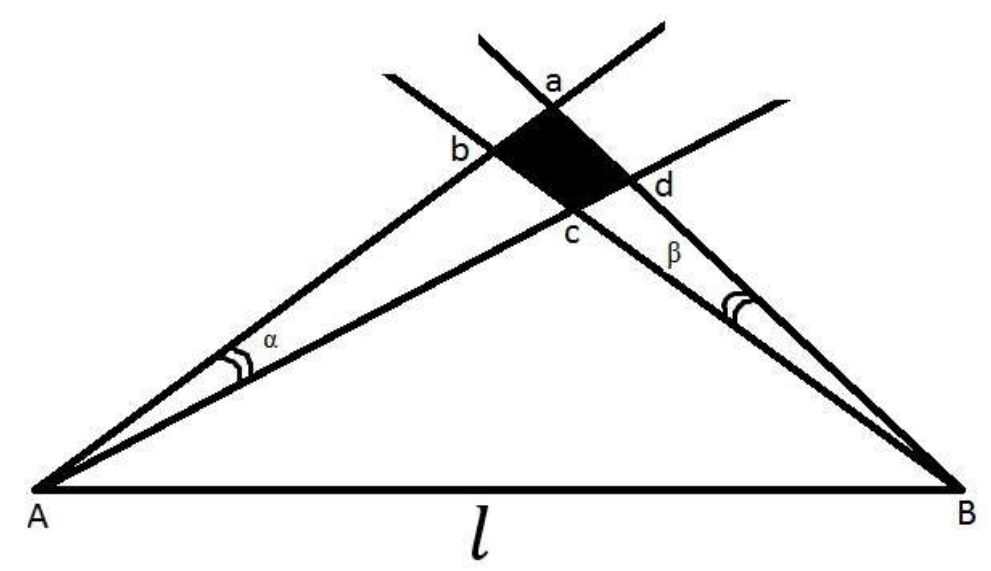

Figure 12 Localization using the null steering principle

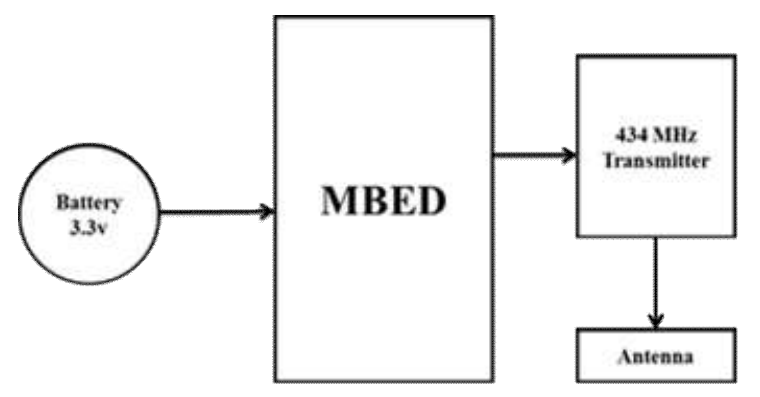

Figure 13 RFID tag block diagram 


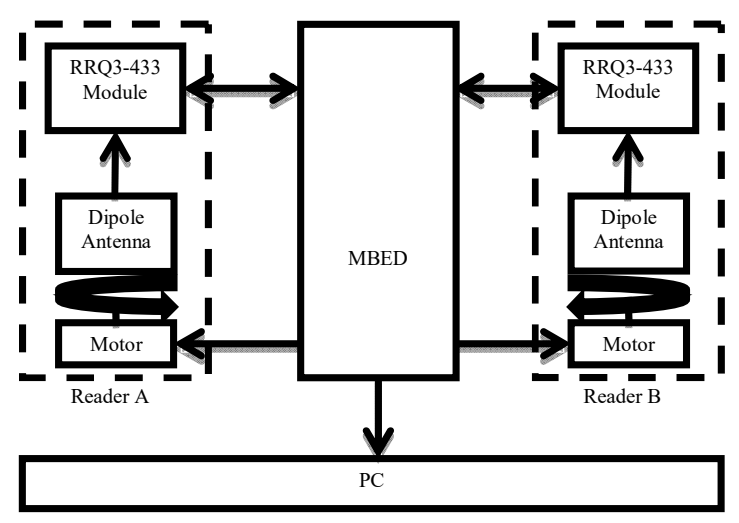

Figure 14 RFID localizer block diagram.

Table 1 Location table for Figure 3

\begin{tabular}{|c|c|c|c|c|}
\hline Tag & \multicolumn{2}{|c|}{ Angle } & \multicolumn{2}{c|}{ Visible } \\
\hline & Min $^{\text {}}$ & Max $^{\mathrm{O}}$ & Yes & No \\
\hline 1 & 60 & 70 & B C D E & A \\
\hline 2 & 70 & 80 & C D E & A B \\
\hline 3 & 80 & 90 & A D E & B C \\
\hline 4 & 90 & 100 & A B E & C D \\
\hline 5 & 100 & 110 & A B C & D E \\
\hline 6 & 110 & 120 & A B C D & E \\
\hline
\end{tabular}

Table 2 Specification for Eureka RFID reader

\begin{tabular}{|c|c|}
\hline Specifications & Details \\
\hline RX Frequency & $868 \mathrm{MHz}$ \\
\hline Range & Up to $100 \mathrm{~m}$ \\
\hline LAN & $10 / 100$ Base-T Ethernet via RJ45 \\
\hline Operating Temperature & $-10^{\circ} \mathrm{C}$ to $+50^{\circ} \mathrm{C}$ \\
\hline Size & $200 \mathrm{~mm} \times 210 \mathrm{~mm} \times 48 \mathrm{~mm}$ \\
\hline weight & $0.7 \mathrm{~kg}$ \\
\hline Supply Voltage & $12 \mathrm{~V} \mathrm{DC}$ \\
\hline
\end{tabular}


Table 3 Measurement results for the angles based on the null steering and RSSI

\begin{tabular}{|c|c|c|}
\hline Angle & $\begin{array}{c}\text { Reader A } \\
\text { (RSSI) }\end{array}$ & $\begin{array}{c}\text { Reader B } \\
\text { (RSSI) }\end{array}$ \\
\hline 90 & 5 & 5 \\
\hline 80 & 2.5 & 5 \\
\hline 70 & 1.3 & 5 \\
\hline 60 & 2.5 & 5 \\
\hline 50 & 5 & 4 \\
\hline 40 & 5 & 1.2 \\
\hline 30 & 5 & 0.7 \\
\hline 20 & 5 & 1.2 \\
\hline 10 & 5 & 4 \\
\hline 0 & 5 & 5 \\
\hline
\end{tabular}

Table 4 Comparison of outdoor localization methods

\begin{tabular}{|c|c|c|c|c|}
\hline Reference & $\begin{array}{r}\text { Number of } \\
\text { readers }\end{array}$ & $\begin{array}{l}\text { GPS is } \\
\text { needed? }\end{array}$ & $\begin{array}{r}\text { Reference tag } \\
\text { is needed? }\end{array}$ & $\begin{array}{l}\text { Antenna } \\
\text { technique }\end{array}$ \\
\hline $\begin{array}{c}\text { Vojtech, Neruda, } \\
\text { Skapa et al. }\end{array}$ & 3 & yes & yes & 8-20 clover leaf antennas \\
\hline $\begin{array}{c}\text { Vojtech, Neruda, } \\
\text { Hrad et al. }\end{array}$ & 3 & no & yes & 8 clover leaf antennas \\
\hline Lucianaz et al. & 1 & yes & no & 1 helical antenna \\
\hline Yang et al. & 2 & yes & no & $\begin{array}{c}2 \text { stub antennas and } 2 \\
\text { helical antennas }\end{array}$ \\
\hline $\begin{array}{r}\text { System proposed } \\
\text { in this paper }\end{array}$ & $1^{*}$ & no & no & 1 dipole antenna ${ }^{\#}$ \\
\hline
\end{tabular}

* moving the reader from one position to another position

\# rotating antenna for required angles $\left(0^{\circ}-360^{\circ}\right)$ 